\title{
MicroRNA-186-3p attenuates tumorigenesis of cervical cancer by targeting MCM2
}

\author{
XIURONG LU, XIAO SONG, XIAOHUI HAO, XIAOYU LIU, \\ XIANYU ZHANG, NA YUAN, HUAN MA and ZHILIN ZHANG \\ Department of Radiotherapy, The First Affiliated Hospital of Hebei North University, \\ Zhangjiakou, Hebei 075000, P.R. China
}

Received November 24, 2020; Accepted April 28, 2021

DOI: $10.3892 / \mathrm{ol} .2021 .12800$

\begin{abstract}
The present study examined the effect of microRNA (miRNA/miR)-186-3p and its target gene, minichromosome maintenance complex component 2 (MCM2), on cervical cancer. Cervical cancer tissues and corresponding normal tissues were collected from 48 patients and bioinformatics analysis was performed to identify the differentially expressed genes in cervical cancer. TargetScan and TarBase were used to identify miRNAs, and reverse transcription-quantitative PCR was conducted to detect and evaluate mRNA expression levels. Additionally, MTT and 5-bromo-2-deoxyuridine assays were performed to examine cell proliferation. Cell adhesion, cell cycle distribution and apoptosis were assessed using cell adhesion, flow cytometry and caspase-3/7 activity assays, respectively. The results revealed that miR-186-3p expression was downregulated in cervical cancer tissues and cells, and it negatively regulated MCM2 expression by directly targeting its 3' untranslated region in cervical cancer. Furthermore, MCM2 facilitated cell proliferation and inhibited cell apoptosis, which were reversed by upregulation of miR-186-3p expression. Collectively, the present study suggested that MCM2 and its negative regulator, miR-186-3p, regulate cervical cancer progression.
\end{abstract}

\section{Introduction}

Cervical cancer was the fourth most common malignant tumour worldwide in 2018, with a high mortality rate among women (1). In 2018, 530,000 women worldwide were diagnosed with cervical cancer, and $60 \%$ of patients with cervical cancer are likely to die $(1,2)$. Human papillomavirus (HPV)

Correspondence to: Dr Xiurong Lu, Department of Radiotherapy, The First Affiliated Hospital of Hebei North University, 12 Changqing Road, Zhangjiakou, Hebei 075000, P.R. China

E-mail: xiurong_lu2@163.com

Key words: cervical cancer, microRNA-186-3p, minichromosome maintenance complex component 2, proliferation, apoptosis, cell cycle is the main risk factor of cervical cancer, and the widespread use of HPV vaccines and virus screening has reduced cervical cancer incidence $(3,4)$. Although treatment methods, such as radiotherapy, chemotherapy and surgery, have been used in the last two decades to improve the survival rate of patients with cervical cancer (5), the underlying mechanism of this tumour remains largely unknown. Therefore, oncogenes involved in cervical cancer carcinogenesis require further exploration.

MicroRNAs (miRNAs/miRs) are non-coding RNAs, 19-25 nucleotides in length, which are involved in the post-transcriptional modification of RNAs by binding to the 3' untranslated region (UTR) of target genes $(6,7)$. Researchers have studied the effect of miR-186 on several types of cancer, including gastric cancer, ovarian cancer, multiple myeloma and melanoma (8-11). Several studies have demonstrated that miR-186 promotes cell apoptosis and inhibits cell proliferation, aerobic glycolysis and metastasis (12-15). Additionally, this miRNA functions as a tumour suppressor in breast cancer by inhibiting the expression of epiregulin (EREG), which promotes glycolysis and enhances cell proliferation (16). Although no studies have explored the function of miR-186-3p in cervical cancer, miR-186-5p has been reported to be downregulated in HPV-infected cervical cancer cells (17). Previous evidence has demonstrated that miR-186 suppresses the epithelial-mesenchymal transition of cervical cancer cells, which promotes apoptosis of cervical cancer cells (18). Furthermore, the long non-coding RNA (lncRNA) antisense RNA in the INK4 locus promotes the progression of cervical cancer by sponging miR-186 (19). However, to the best of our knowledge, the function and underlying mechanism of miR-186-3p remain elusive.

Minichromosome maintenance complex component 2 (MCM2) is located on chromosome 3 q21.3 and comprises 17 exons (20). It encodes minichromosome maintenance complex (MCM) involved in the initiation of eukaryotic genome replication (21). MCM2 is frequently upregulated in breast cancer (22), melanoma (23), ovarian cancer (24) and oral squamous cell carcinoma (25). Several bioinformatics studies have suggested that MCM2 is a key gene for diagnosis and prediction of the occurrence of cervical cancer (26-28). Although a study regarding differentially expressed miRNAs and genes has also revealed aberrant MCM2 expression (29), to the best of our knowledge, researchers are yet to clarify the 
oncogenic function of MCM2 in cervical cancer and its regulatory network, especially the interaction between miR-186-3p and MCM2.

The present study aimed to investigate the oncogenic effects of MCM2 and miR-186-3p in cervical cancer. It was hypothesised that by directly targeting MCM2, miR-186-3p suppresses MCM2 expression and cervical cancer progression. These results may provide novel insights into the oncogenic functions of miR-186-3p and MCM2 in cervical cancer and enhance the understanding of oncogenes and their regulatory network profiles.

\section{Materials and methods}

Bioinformatics analysis. The mRNA expression profiles [GSE7803 (30) and GSE63514 (31)] were downloaded from Gene Expression Omnibus DataSets (https://www.ncbi.nlm. nih.gov/gds/?term=) and were used to screen the upregulated genes with adjusted P-values set at $<0.05$ and log fold change at $>1.5$. Subsequently, the Search Tool for the Retrieval of Interacting Genes/Proteins database (STRING; version 11.0; https://string-db.org/) was used for biological process enrichment analysis of upregulated genes. Next, the expression pattern of upregulated genes was further analysed using data from The Cancer Genome Atlas (TCGA; Project ID, CESC; https://portal.gdc.cancer.gov/). Finally, the miRNA was identified using TargetScan 7.1 (http://www.targetscan.org/vert_71/) and TarBase v8 (http://carolina.imis.athena-innovation. gr/diana_tools/web/index.php? $r=$ tarbasev8/index), which could predict the upstream miRNAs of a key gene. Venny 2.1.0 (http://bioinfogp.cnb.csic.es/tools/venny/) was used to overlap the miRNAs from the two databases (TargetScan 7.1 and TarBase v8).

Clinical specimens. Cervical cancer tissues and corresponding normal tissues ( $3 \mathrm{~cm}$ from tumour tissues) were collected from 48 female patients (mean age, 48 years; age range, 36-67 years) diagnosed with cervical cancer at The First Affiliated Hospital of Hebei North University (Zhangjiakou, China) between September 2017 and October 2018. Biopsy samples were obtained and stored in liquid nitrogen $\left(-196^{\circ} \mathrm{C}\right)$. The inclusion criteria were: i) Patients were diagnosed with cervical cancer; ii) patient's information had obtained; and iii) patients signed the consent forms. The exclusion criteria were: i) Patients had other types of disease; and ii) patients underwent chemotherapy, radiotherapy or other therapies. Diagnostic test results were independently confirmed by two pathologists. The present study was approved by the Ethics Committee of The First Affiliated Hospital of Hebei North University (Zhangjiakou, China). The clinical characteristics of the patients are summarised in Table I. All samples were graded as I, II, III and IV based on The International Federation of Gynecology and Obstetrics staging system (32).

Cell culture and transfection. Human cervical cancer cell lines (HeLa, CaSki, SiHa and C33A) and a normal cervical epithelial cell line (HcerEpic) were purchased from the National Infrastructure of Cell Line Resource. The small interfering RNA (siRNA/si) of MCM2 (si-MCM2; 5'-CAG GTGACAGACTTTATCAAA-3') and the scrambled negative control (si-NC; 5'-UUCUCCGAACGUGUCACGUTT-3') were obtained from Shanghai GenePharma Co., Ltd., and the miR-186-3p mimic (5'-GCCCAAAGGUGAAUUUUUU GGG-3'), miR-186-3p inhibitor (5'-CCCAAAAAAUUCACC UUUGGGC-3'), mimic-NC (5'-UCACAACCUCCUAGAAAG AGUAGA-3') and inhibitor-NC (5'-UUUGUACUACACAAAA GUACUG-3') were purchased from Guangzhou RiboBio Co., Ltd. All cells were cultured in RPMI-1640 medium (Gibco; Thermo Fisher Scientific, Inc.) supplemented with penicillin $(100 \mathrm{U} / \mathrm{ml})$, streptomycin $(100 \mu \mathrm{g} / \mathrm{ml})$ and FBS [10\% (v/v); Gibco; Thermo Fisher Scientific, Inc.]. The cells were cultured and incubated in air containing $5 \% \mathrm{CO}_{2}$ at $37^{\circ} \mathrm{C}$. All cell transfections were performed using Lipofectamine ${ }^{\circledR} 2000$ Transfection Reagent (Thermo Fisher Scientific, Inc.). The transfection concentration of si-MCM2, si-NC, miR-186-3p mimic, mimic-NC, miR-186-3p inhibitor and inhibitor-NC was $50 \mathrm{nM}$. After $48 \mathrm{~h}$ of transfection at $37^{\circ} \mathrm{C}$, transfection efficiency was determined using reverse transcription-quantitative PCR (RT-qPCR). The cells in the control (CON) group were not transfected. The cell function experiments were performed at $48 \mathrm{~h}$ after transfection.

$R T-q P C R$. All cells were harvested and allowed to reach $\sim 90 \%$ confluence as described previously (33). The cells were first washed with PBS ( $\mathrm{pH}$ 7.4), and total RNA was extracted using TRIzol ${ }^{\circledR}$ reagent (Thermo Fisher Scientific, Inc.) according to the manufacturer's protocol. For tissues, total RNA was also extracted using TRIzol ${ }^{\circledR}$ reagent (Thermo Fisher Scientific, Inc.). Subsequently, cDNA was synthesised using the PrimeScript RT-PCR Kit (Takara Bio, Inc.) at $37^{\circ} \mathrm{C}$ for $15 \mathrm{~min}$ and $85^{\circ} \mathrm{C}$ for $5 \mathrm{sec}$. RT-qPCR was performed using a One Step SYBR PrimeScript RT-PCR Kit (Takara Bio, Inc.) with the following thermocycling conditions: $42^{\circ} \mathrm{C}$ for $5 \mathrm{~min}$, $95^{\circ} \mathrm{C}$ for $10 \mathrm{sec}, 40$ cycles of $95^{\circ} \mathrm{C}$ for $5 \mathrm{sec}$ and $60^{\circ} \mathrm{C}$ for $30 \mathrm{sec}$. Gene expression was examined using the 7500 Real-Time PCR System (Applied Biosystems; Thermo Fisher Scientific, Inc.) and the $2^{-\Delta \Delta C q}$ method (34) was used to calculate relative expression. U6 and GAPDH were used as reference genes for miRNA and mRNA, respectively. The primer sequences used for RT-qPCR are listed in Table II.

Western blotting. First, $5 \times 10^{5} \mathrm{HeLa}$ and $\mathrm{SiHa}$ cells were suspended in lysis buffer [50 mM Tris-HCl, $\mathrm{pH} 8.0,150 \mathrm{mM}$ $\mathrm{NaCl}, 0.5 \mathrm{mM} \mathrm{MgCl}_{2}, 10 \%$ glycerol, $1 \%$ Triton X-100 and $0.1 \%$ sodium dodecyl sulfate (SDS)] containing the protease inhibitor cocktail (Roche Diagnostics) on ice for $30 \mathrm{~min}$. Subsequently, the samples were centrifuged for $15 \mathrm{~min}$ at $12,000 \times \mathrm{g}$ at $4^{\circ} \mathrm{C}$. After the supernatants were collected, protein concentrations were measured using the Dc Bio-Rad Protein Assay Kit (Bio-Rad Laboratories, Inc.). Proteins (20 $\mu \mathrm{g} /$ lane) extracted from the cells were separated using a $10 \%$ SDS polyacrylamide gel and subsequently transferred to PVDF membranes. The membranes were blocked with $5 \%$ non-fat milk for $2 \mathrm{~h}$ at $25^{\circ} \mathrm{C}$ and then incubated overnight at $4^{\circ} \mathrm{C}$ with the anti-MCM2 antibody (dilution, 1:1,000; cat. no. ab4461; Abcam) and the anti-GAPDH antibody (dilution, 1:1,000; cat. no. ab128915; Abcam) followed by the HRP Anti-Rabbit IgG antibody (dilution, 1:5,000; cat. no. ab270144; Abcam) for $2 \mathrm{~h}$ at $25^{\circ} \mathrm{C}$. The blots were developed using the Immobilon Western Chemiluminescent HRP Substrate 
Table I. Clinical characteristics of 48 patients with cervical cancer.

\begin{tabular}{lr}
\hline Characteristics & No. $(\%)(\mathrm{n}=48)$ \\
\hline Age, years & \\
$\leq 48$ & $34(70.8)$ \\
$>48$ & $14(29.2)$ \\
Tumor differentiation & \\
Well & $6(12.5)$ \\
Moderate & $18(37.5)$ \\
Poor & $24(50.0)$ \\
Tumor size, cm & \\
$\leq 4$ & $37(77.1)$ \\
$>4$ & $11(22.9)$ \\
Histological type & \\
Squamous carcinoma & $32(66.7)$ \\
Adenocarcinoma & $10(20.8)$ \\
Other & $6(12.5)$ \\
FIGO stage & \\
I & $11(22.9)$ \\
II & $33(68.7)$ \\
III & $3(6.3)$ \\
IV & $17(2.1)$ \\
Lymph nodes status & \\
Positive & \\
Negative & \\
Vascular invasion & \\
Positive & \\
Negative & $(56.4)$ \\
\hline & \\
& \\
\hline
\end{tabular}

FIGO, The International Federation of Gynecology and Obstetrics.

(cat. no. WBKLS0500; Merck KGaA). Densitometry was performed using Image J 1.48 (National Institutes of Health).

MTT assay. HeLa and $\mathrm{SiHa}$ cells at $60 \%$ confluence were transfected using Lipofectamine ${ }^{\circledR} 2000$ Transfection Reagent (Thermo Fisher Scientific, Inc.) according to the manufacturer's protocol. Subsequently, the cells were treated with trypsin at $37^{\circ} \mathrm{C}$ for $60 \mathrm{sec}$ and seeded into 96 -well plates at a density of $3 \times 10^{3}$ cells/well. After a transfection period of $24 \mathrm{~h}, 20 \mu \mathrm{l} \mathrm{MTT}$ was added to the 96-well plates. Three replicates were performed for each group. After $4 \mathrm{~h}$, the supernatant was discarded, $150 \mu \mathrm{l}$ DMSO was added to each well, and the mixture was incubated at $37^{\circ} \mathrm{C}$ for $10 \mathrm{~min}$. Finally, the absorbance value of the cells at $570 \mathrm{~nm}$ was measured at $0,24,48$ and $72 \mathrm{~h}$.

5-bromo-2-deoxyuridine (BrdU) assay. This assay was performed using the BrdU Cell Proliferation ELISA kit (cat. no. ab126556; Abcam). BrdU was first dissolved in DMSO (Thermo Fisher Scientific, Inc.). The HeLa and SiHa cells were seeded in 96-well plates at a density of $3 \times 10^{3}$ cells/well and incubated for $48 \mathrm{~h}$ at $37^{\circ} \mathrm{C}$. Subsequently, the BrdU solution was added to label the cells according to the manufacturer's protocol. Next, the labelling solution was removed, and the cells were washed twice with PBS, fixed with paraformaldehyde at $4^{\circ} \mathrm{C}$ for $20 \mathrm{~min}$ and treated with Triton X-100 permeabilization buffer. The cells were subsequently treated with the anti-BrdU antibody (100 $\mu \mathrm{l} /$ well) at room temperature for $1 \mathrm{~h}$. After adding the anti-mouse IgG antibody (100 $\mu \mathrm{l} /$ well $)$ and incubating the mixture at room temperature for $30 \mathrm{~min}$, the absorbance value at $450 \mathrm{~nm}$ was determined using a microplate reader.

Cell adhesion assay. To test the adhesive ability of cervical cancer cells, the HeLa and $\mathrm{SiHa}$ cells $\left(3 \times 10^{4}\right.$ cells/well) were seeded in 6-well plates coated with type I collagen (BD Biosciences). After a 60-min incubation, the non-adherent cells were removed, and MTT (Sigma-Aldrich; Merck KGaA) was added for $4 \mathrm{~h}$. The medium was then replaced with $150 \mu \mathrm{l}$ DMSO for $20 \mathrm{~min}$. Subsequently, the absorbance value was determined at $570 \mathrm{~nm}$.

Cell migration assay. A chamber (cat. no. 3422; Corning, Inc.) in a 24-well plate was prepared for the cell migration assay using HeLa and SiHa cells. Cell culture medium with $10 \%$ FBS was added to the lower chamber, and $200 \mu \mathrm{l}$ cell suspensions $\left(2 \times 10^{5}\right.$ cells) in serum-free cell culture medium were added to the upper chamber for a $24-\mathrm{h}$ incubation at $37^{\circ} \mathrm{C}$. Subsequently, the cells that migrated to the lower chamber were fixed with $100 \%$ methanol for $30 \mathrm{~min}$ at $25^{\circ} \mathrm{C}$ and stained with $0.5 \%$ crystal violet (cat. no. C0775; Sigma-Aldrich; Merck $\mathrm{KGaA}$ ) for $20 \mathrm{~min}$ at $25^{\circ} \mathrm{C}$. Finally, images of five different fields from each chamber were randomly captured using a light microscope (Olympus Corporation).

Determination of caspase-3/7 activity. Cell apoptosis was detected using a caspase-3/7 activity assay kit (cat. no. E607103; Sangon Biotech Co., Ltd.) according to the manufacturer's protocol. The HeLa and SiHa cells $\left(2 \times 10^{4}\right.$ cells/well) were seeded into a 96-well plate and cultured for $48 \mathrm{~h}$. The cells were lysed and centrifuged at $1,000 \mathrm{x} \mathrm{g}$ for $20 \mathrm{~min}$ at $4^{\circ} \mathrm{C}$. Subsequently, the protein concentration was determined using a BCA assay (Thermo Fisher Scientific, Inc.). The supernatant containing $50 \mu \mathrm{g}$ protein was added to the caspase-3/7 assay loading solution $(100 \mu \mathrm{l})$ and the mixture was incubated at $37^{\circ} \mathrm{C}$ for $1 \mathrm{~h}$ in the absence of light. Finally, caspase-3/7 activity was determined at excitation/emission $=490 / 525 \mathrm{~nm}$ using a microplate reader.

Cell cycle assay. The cell cycle kit was obtained from Beckman Coulter, Inc. (cat. no. C03551) for the cell cycle assay. HeLa and $\mathrm{SiHa}$ cells $\left(3 \times 10^{6}\right.$ cells/well) were seeded in a 6-well plate and transfected with si-MCM2 and NC siRNA for $24 \mathrm{~h}$. The cells were harvested using trypsin, fixed with $70 \%$ ethanol at $4{ }^{\circ} \mathrm{C}$ overnight, incubated with RNase A at $37^{\circ} \mathrm{C}$ for $1 \mathrm{~h}$, and stained with propidium iodide (included in the cell cycle kit) for $20 \mathrm{~min}$ at $4^{\circ} \mathrm{C}$. The cells in different phases of the cell cycle were measured using a flow cytometer (FACSCalibur; BD Biosciences) and the results were analysed using ModFit LT v3.3 software (Verity Software House, Inc.).

RNA pull-down. The HeLa and SiHa cells were transfected with $50 \mathrm{nM}$ biotinylated miR-186-3p (Bio-miR-186-3p; 
Table II. Primer sequences for reverse transcription-quantitative PCR.

\begin{tabular}{ll} 
Gene & \multicolumn{1}{c}{ Primer sequences $\left(5^{\prime}-3^{\prime}\right)$} \\
\hline miR-186-3p & Forward: GCCCAAAGGTGAATTTTTTGGG \\
U6 & Reverse: CAGTGCGTGTCGTGGAGT \\
MCM2 & Forward: CTCGCTTCGGCAGCACA \\
& Reverse: AACGCTTCACGAATTTGCGT \\
GAPDH & Forward: AGCACTTGATGAACTCGGGG \\
& Reverse: AAGCCAACAGATACCAGCGT \\
& Forward: GGAGCGAGATCCCTCCAAAAT \\
\end{tabular}

MCM2, minichromosome maintenance complex component 2; miR-186-3p, microRNA-186-3p.

5'-GCCCAAAGGUGAAUUUUUUGGG-biotin-3'; Guangzhou RiboBioCo., Ltd.) and biotinylated NC (Bio-NC; 5'-UCACAAC CUCCUAGAAAGAGUAGA-biotin-3'; Guangzhou RiboBio Co., Ltd.) using Lipofectamine ${ }^{\circledR} 2000$ Transfection Reagent (Thermo Fisher Scientific, Inc.). After a transfection period of $48 \mathrm{~h}$ at $37^{\circ} \mathrm{C}$, the cells were harvested, lysed using $500 \mu \mathrm{llysis}$ buffer (25 mM Tris-HCl pH 7.0, $70 \mathrm{mM} \mathrm{KCl,} 2.5 \mathrm{mM}$ EDTA, $80 \mathrm{U} / \mathrm{ml}$ of a RNAse inhibitor) and centrifuged at 12,000 x g at $4^{\circ} \mathrm{C}$ for $15 \mathrm{~min}$. A total of $10 \mu \mathrm{l}$-280 streptavidin magnetic beads (cat. no. 11205D; Invitrogen; Thermo Fisher Scientific, Inc.) washed with washing buffer containing $250 \mu \mathrm{g}$ RNase-free BSA (Thermo Fisher Scientific, Inc.) and $100 \mu \mathrm{g}$ yeast tRNA in $500 \mu 125 \mathrm{mM}$ Tris- $\mathrm{HCl}$ (pH 7.5), $70 \mathrm{mM} \mathrm{KCl}$, $2.5 \mathrm{mM}$ EDTA and $0.05 \% \mathrm{NP}-40$ were subsequently utilized to incubate the $500 \mu \mathrm{l}$ cell lysates. The beads were coated with RNase-free BSA and yeast tRNA (both from Sigma-Aldrich; Merck KGaA) to prevent non-specific binding of RNA or protein complexes. Subsequently, the beads were incubated for $3 \mathrm{~h}$ at $4^{\circ} \mathrm{C}$ and washed with cold lysis buffer three times and with high salt buffer $(0.1 \%$ SDS, $1 \%$ Triton X-100, $2 \mathrm{mM}$ EDTA, $20 \mathrm{mM}$ Tris- $\mathrm{HCl}$, $\mathrm{pH} 8.0$, and $500 \mathrm{mM} \mathrm{NaCl})$. The biotin-miRNA/mRNA complex was collected after centrifugation at 5,000 x g for $30 \mathrm{sec}$ at $4^{\circ} \mathrm{C}$. Finally, the combined RNA was extracted using TRIzol reagent, and the relative expression levels of MCM2 were measured using RT-qPCR.

Dual-luciferase reporter assay. Fragments of the 3' UTR region of MCM2, which contained the putative binding site for $\mathrm{miR}-186-3 \mathrm{p}$, were cloned into the luciferase reporter vector (psiCHECK-2), which was named the wild-type (wt) vector. The mutant (mut) vector harboured the mutated binding site of MCM2 3' UTR. The HeLa and SiHa cells at a density of $2 \times 10^{5}$ cells/well were seeded in 24-well plates and cultured for $24 \mathrm{~h}$. When the density of the cells increased by $50 \%$, Lipofectamine ${ }^{\circledR} 2000$ Transfection Reagent was used to transfect $100 \mathrm{ng}$ pMIR-REPORT plasmid (Addgene, Inc.), which contained firefly luciferase, $60 \mathrm{pmol}$ mimic-NC or miR-186-3p mimic, and $10 \mathrm{ng}$ psiCHECK-2-wt or psiCHECK-2-mut plasmid. Subsequently, the cells were harvested, and the Renilla and firefly activities were examined using the Dual-Luciferase Reporter Assay Kit (Promega Corporation) after $48 \mathrm{~h}$ of transfection. Finally, the luciferase activity was calculated and normalized to Renilla activity.

Statistical analysis. SPSS 13.0 (SPSS, Inc.) and GraphPad 7.0 (GraphPad Software, Inc.) were used for statistical analyses. The statistical comparison between two groups was performed using a paired Student's t-test, while that among more than two groups was performed using one-way ANOVA with Dunnett's or Tukey's post hoc test. Pearson's correlation analysis was conducted to investigate the correlation between MCM2 expression and miR-186-3p expression. All data are presented as the mean \pm standard deviation of three independent experiments. $\mathrm{P}<0.05$ was considered to indicate a statistically significant difference.

\section{Results}

MCM2 is a key gene in cervical cancer. The mRNA expression profile was downloaded from the Gene Expression Omnibus DataSets. With adjusted P values set at $<0.05$ and $\log$ fold change at $>1.5,115$ upregulated genes were identified in both the GSE7803 dataset and the GSE63514 dataset (Fig. 1A). These 115 genes were uploaded to the STRING database for biological process enrichment analysis, which revealed that the 'Cell cycle process', 'Cell cycle' and ' $\mathrm{G}_{1} / \mathrm{S}$ transition of the mitotic cell cycle' were the key biological processes (Fig. 1B). A total of 12 genes involved in these three biological processes were screened (Fig. 1C). Data from TCGA revealed that among the 12 genes, the expression levels of CDKN2A, MCM2, RRM2 and TYMS were upregulated in cervical squamous cell carcinoma (Fig. 1D). After reviewing the literature, it was identified that MCM2 expression is upregulated in clinical samples of cervical cancer $(26,28,35)$; however, to the best of our knowledge, its function and regulatory mechanisms in cervical cancer cells have not yet been explored. Therefore, MCM2 was identified as the gene of interest.

MCM2 expression is upregulated in cervical cancer tissues and cell lines. MCM2 expression in cervical cancer and normal tissues was first examined using RT-qPCR. The results revealed that the expression levels of MCM2 were significantly upregulated in tumour tissues compared with normal tissues (Fig. 2A). 
A

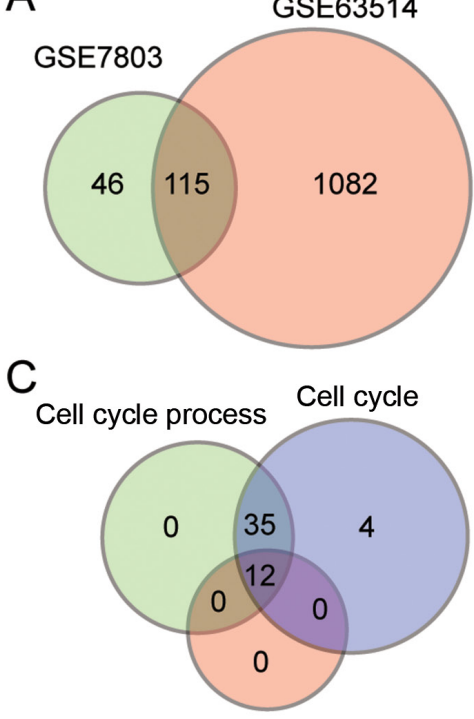

B

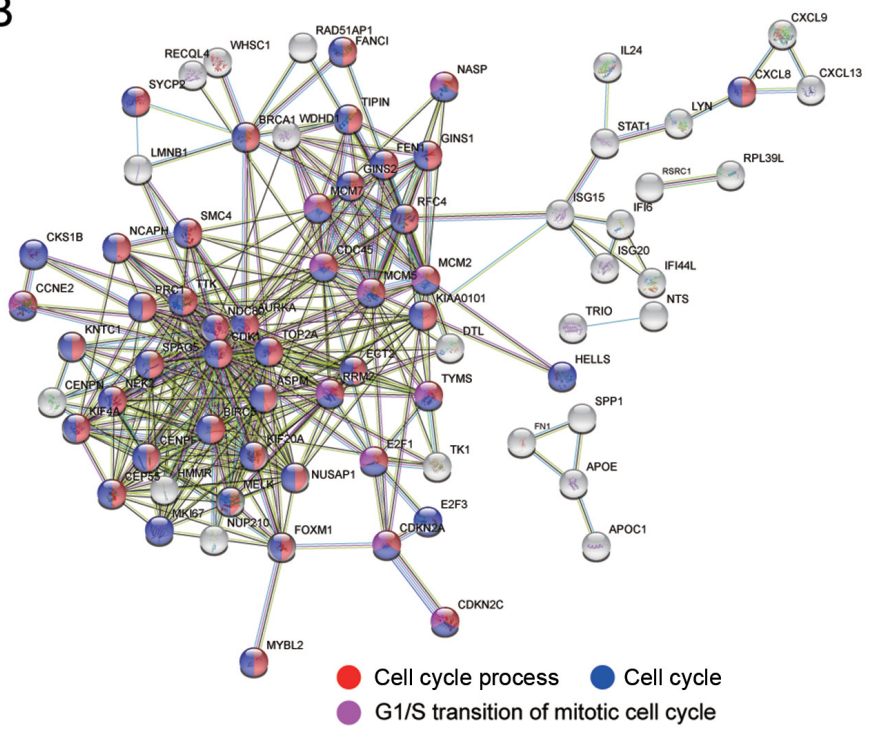

G1/S transition of mitotic cell cycle

D

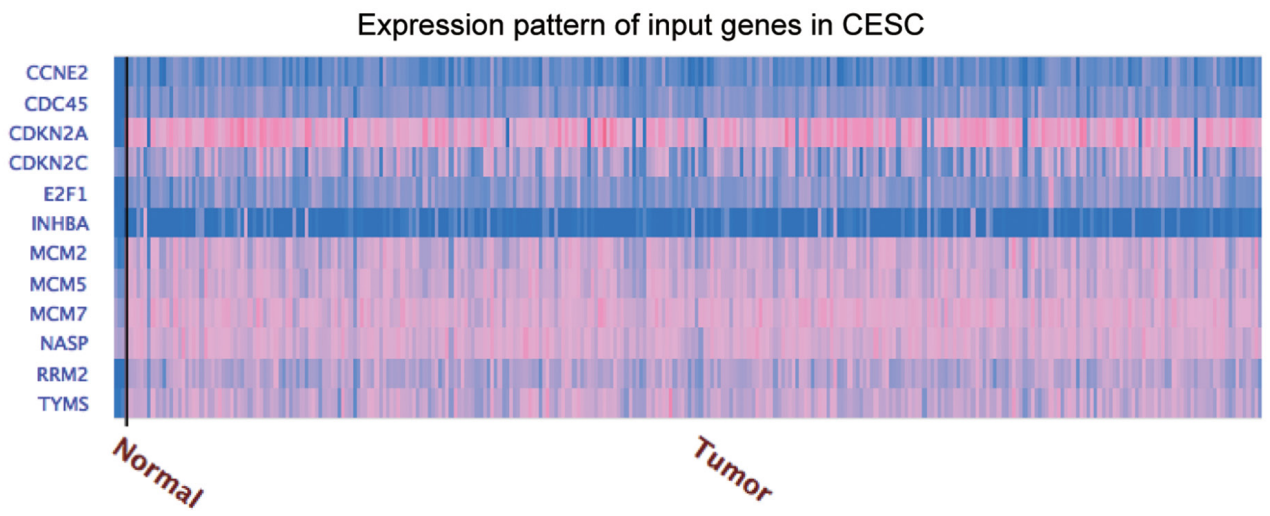

$\log 2(\mathrm{TPM}+1)$

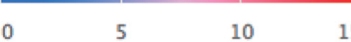

Figure 1. MCM2 is a key gene in cervical cancer. (A) A total of 115 upregulated genes with adjusted $\mathrm{P}<0.05$ and log fold change $>1.5$ were identified in both GSE7803 and GSE63514. (B) 'Cell cycle process', 'Cell cycle' and ' $\mathrm{G}_{1} / \mathrm{S}$ transition of mitotic cell cycle' were identified as the key biological processes according to Search Tool for the Retrieval of Interacting Genes/Proteins analysis. (C) A total of 12 genes were involved in three biological processes, including 'Cell cycle process', 'Cell cycle' and ' $\mathrm{G}_{1} / \mathrm{S}$ transition of mitotic cell cycle'. (D) Expression levels of 12 genes in CESC according to The Cancer Genome Atlas analysis. CESC, cervical squamous cell carcinoma; MCM2, minichromosome maintenance complex component 2; TPM, transcripts per million.

In addition, RT-qPCR demonstrated that the expression levels of MCM2 mRNA were higher in cervical cancer cell lines (HeLa, CaSki, SiHa and C33A) than in the normal cervical epithelial cell line (HCerEpiC; Fig. 2B). Since the expression levels of MCM2 in HeLa and SiHa cells were higher than those in the other cell lines, these two cell lines were selected to conduct MCM2 knockdown experiments using siRNA to verify the function of MCM2 in cervical cancer. The results revealed that MCM2 expression was successfully downregulated with a gene silencing efficiency $>70 \%$ in the si-MCM2 group compared with the control (CON) group (Fig. 2C). Additionally, it was identified that protein expression in the si-MCM2 group was decreased by $80 \%$ compared with that in the CON group (Fig. 2D).

Effects of MCM2 knockdown on cervical cancer cells. To evaluate the oncogenic function of MCM2, several experiments were performed using cervical cancer cells. The results of the MTT assay demonstrated that the proliferation of cancer cells was significantly reduced after transfection with si-MCM2 at 48 and $72 \mathrm{~h}$ compared with that of cells in the CON group (Fig. 3A). Similar results were observed using the BrdU assay, demonstrating that si-MCM2 inhibited cell proliferation compared with the CON group (Fig. 3B). Next, the present study examined whether MCM2 enhanced cell adhesion, and it was revealed that the reduced MCM2 expression by artificial knockdown impaired the adhesion capability of the cells by $>50 \%$ (Fig. 3C). Additionally, the present study investigated the effect of MCM2 on the apoptosis of cancer cells using a caspase-3/7 activity assay. MCM2 knockdown increased the caspase-3/7 activity by 6 -fold compared with that in the CON group, suggesting that MCM2 acted as a strong anti-apoptotic agent (Fig. 3D). Additionally, cell migration was significantly downregulated following MCM2 knockdown (Fig. 3E). Flow cytometric analyses revealed that the 


\section{A}
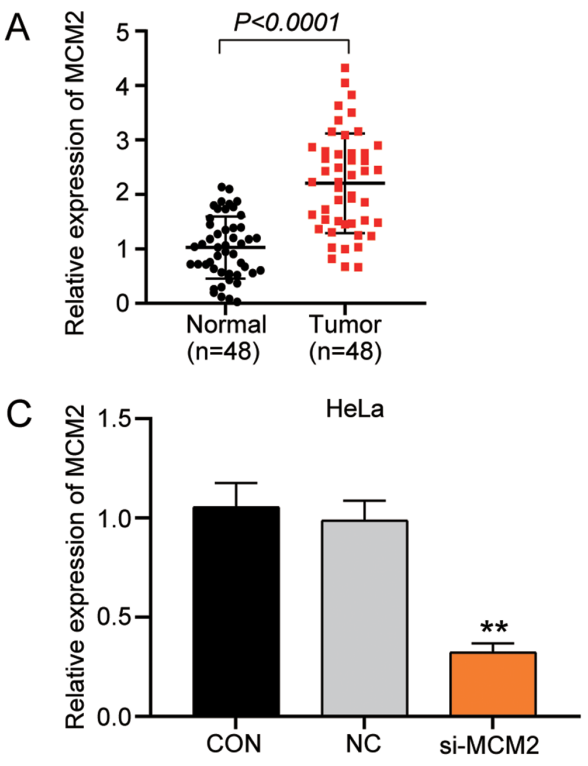

$\mathrm{D}$

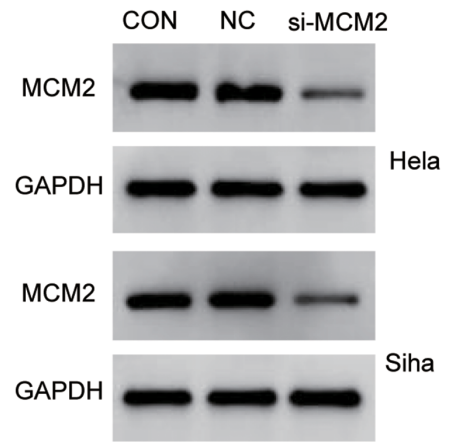

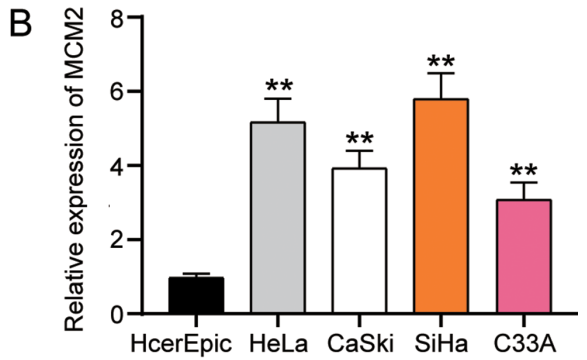
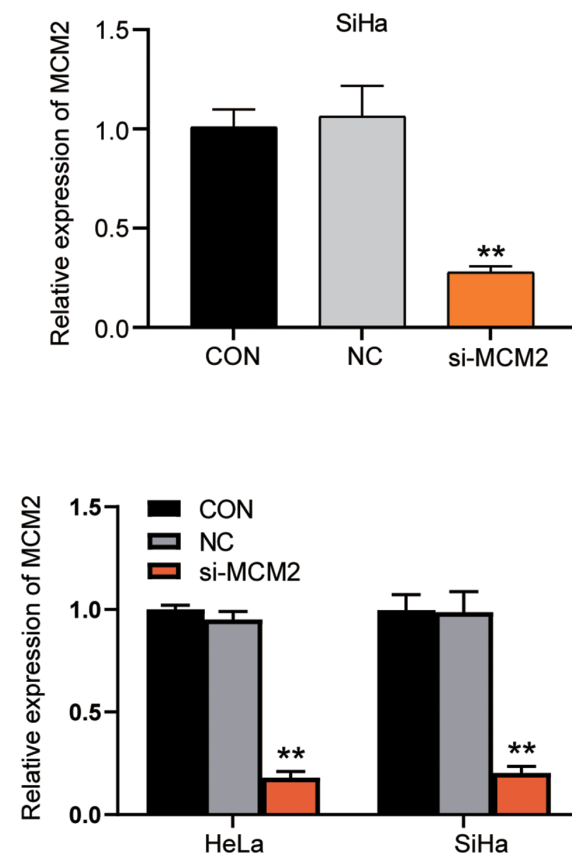

Figure 2. MCM2 expression is upregulated in cervical cancer tissues and cell lines. (A) Expression levels of MCM2 in tumor tissues and the corresponding non-tumor tissues. $\mathrm{P}<0.0001$ (paired Student's t-test). (B) Expression levels of MCM2 were measured in HcerEpic normal cervical epithelial cells and cervical cancer cell lines, including HeLa, CaSki, SiHa and C33A cells. ${ }^{* *} \mathrm{P}<0.001$ vs. HcerEpic cells (one-way ANOVA with Dunnett's post hoc test). (C) Transfection efficiency of si-MCM2 was detected by reverse transcription-quantitative PCR. ${ }^{* *} \mathrm{P}<0.001$ vs. CON group (one-way ANOVA with Dunnett's post hoc test). (D) Transfection efficiency of si-MCM2 was detected by western blotting. All bands are from different parts of the same gel. ${ }^{* *} \mathrm{P}<0.001 \mathrm{vs}$. CON group (one-way ANOVA with Tukey's post hoc test). CON, blank control; MCM2, minichromosome maintenance complex component 2; NC, negative control; si, small interfering RNA.

MCM2 downregulation increased the proportion of cells in the $\mathrm{G}_{0} / \mathrm{G}_{1}$ phase, whereas the proportion of cells in the $\mathrm{G}_{2} / \mathrm{M}$ phase was reduced compared with that in the $\mathrm{CON}$ group, indicating that silencing of MCM2 induced $\mathrm{G}_{0} / \mathrm{G}_{1}$ phase arrest (Fig. 3F and $\mathrm{G}$ ). Overall, these results suggested that MCM2 served a crucial role in promoting cell proliferation and inhibiting cell apoptosis in cervical cancer cells.

Effect of miR-186-3p on MCM2. The online softwares TargetScan and TarBase were used to explore the underlying mechanism by which MCM2 regulates cervical cancer cell behaviours and to identify miRNAs that could regulate MCM2 expression. After Venny 2.1.0 analysis, it was identified that miR-186-3p was the only miRNA identified by both databases (Fig. 4A). Furthermore, miR-186-3p targeted the 3' UTR region of MCM2 (Fig. 4B). Subsequently, the miR-186-3p mimic and its negative control (mimic NC) were successfully transfected into HeLa and $\mathrm{SiHa}$ cells (Fig. 4C). Additionally, a wt and a mut plasmid encoding the 3' UTR region of MCM2 were constructed and a luciferase reporter assay was performed to verify the effect of miR-186-3p on MCM2. The results demonstrated that miR-186-3p overexpression significantly decreased the luciferase activity of MCM2-wt-3' UTR to half of that of the mimic NC group; however, the mut counterpart did not exhibit the same tendency, demonstrating that miR-186-3p bound to the 3' UTR of MCM2 (Fig. 4D). The interaction between miR-186-3p and MCM2 was assessed using an RNA pull-down assay, and it was revealed that the relative expression levels of MCM2 increased after transfection with Bio-miR-186-3p compared with Bio-NC (Fig. 4E). Furthermore, the expression pattern of miR-186-3p in cervical cancer tissues was analysed. The findings revealed that the expression levels of miR-186-3p were downregulated in tumour tissues (Fig. 4F) and that these were negatively correlated with MCM2 expression (Fig. 4G). Furthermore, the expression levels of miR-186-3p in normal cervical epithelial cells and cancer cells were measured and it was revealed that miR-186-3p expression was downregulated in HeLa and SiHa cells (Fig. 4H). Overall, these findings indicated that miR-186-3p could target MCM2 and was negatively associated with MCM2 expression. 

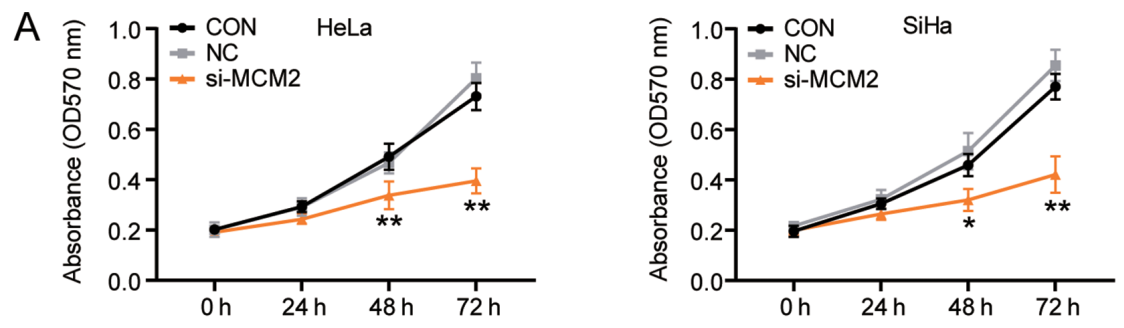

B

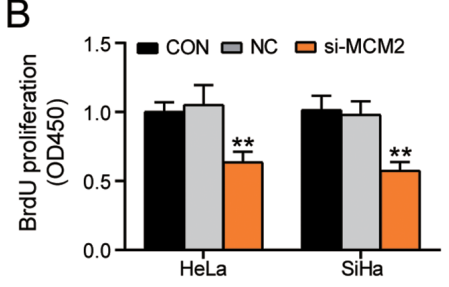

C

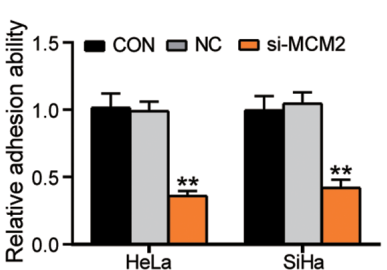

D

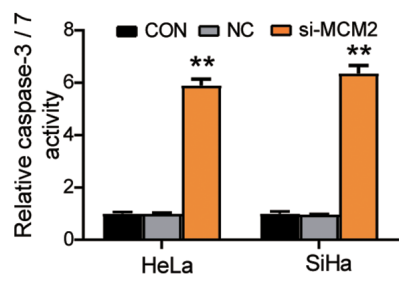

E

CON NC si-MCM2
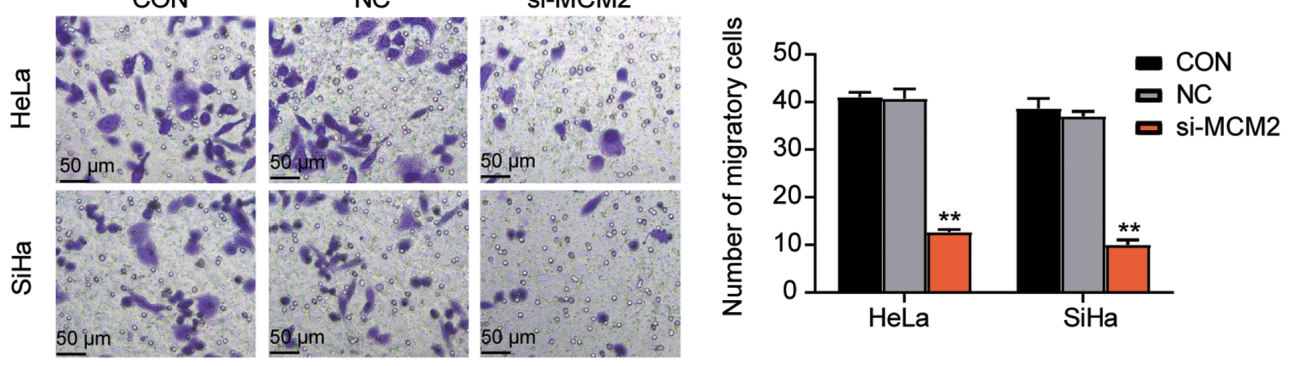

F

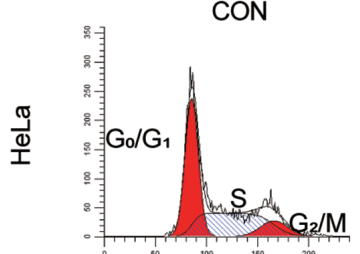

$\mathrm{NC}$

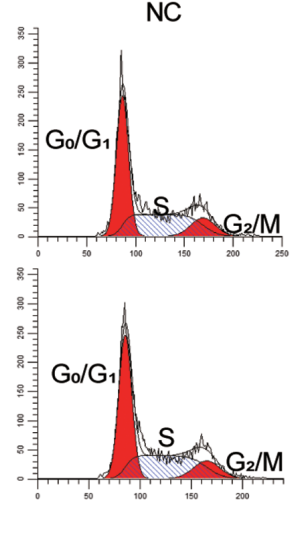

si-MCM2
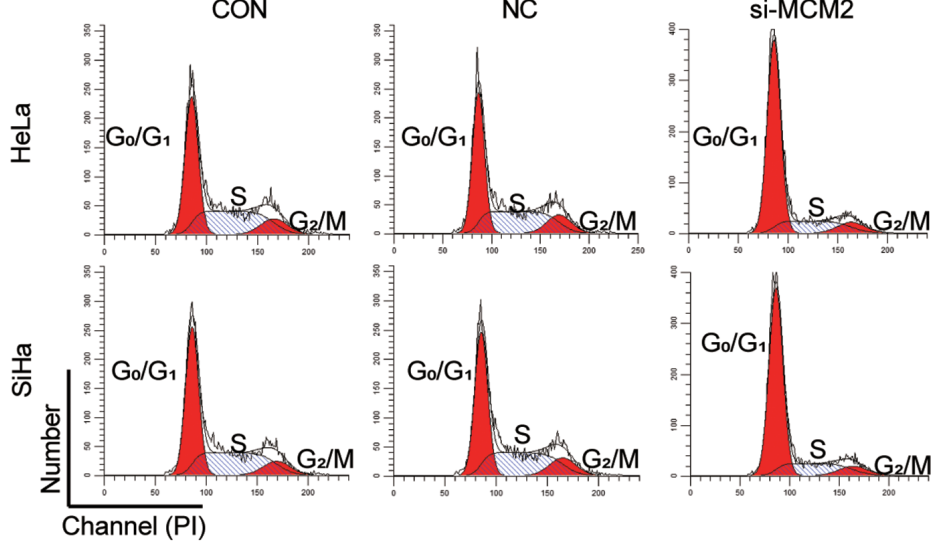

G
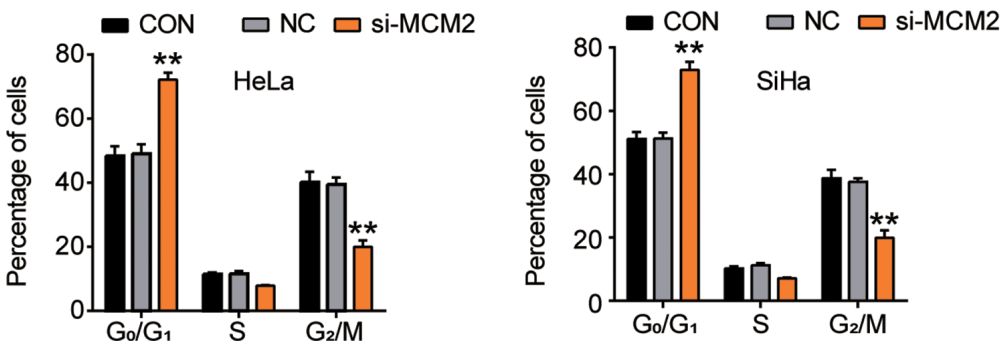

Figure 3. Knockdown of MCM2 attenuates proliferation, cell adhesion and $\mathrm{G}_{0} / \mathrm{G}_{1}$ to $\mathrm{S}$ transition, but enhances apoptosis of cervical cancer cells. (A) Cell proliferation was decreased after silencing of MCM2 expression at 48 and $72 \mathrm{~h}$. (B) Knockdown of MCM2 inhibited cell proliferation examined using a BrdU assay. (C) Cell adhesion ability assay for the si-MCM2 group, NC group and the CON group. (D) Effect of MCM2 on cell apoptosis was examined using a caspase-3/7 activity assay. (E) Cell migration assay for si-MCM2 group, NC group and the control group. Scale bar, $50 \mu \mathrm{m}$. (F) Representative images of cell cycle in different transfection groups. (G) Cell cycle distribution in different transfection groups was calculated. ${ }^{*} \mathrm{P}<0.05$, ${ }^{* *} \mathrm{P}<0.001$ vs. $\mathrm{CON}$ group (one-way ANOVA with Tukey's post hoc test). BrdU, 5-bromo-2-deoxyuridine; CON, blank control; MCM2, minichromosome maintenance complex component 2; $\mathrm{NC}$, negative control; OD, optical density; si, small interfering RNA.

Effects of MCM2 on cervical cancer cells could be reversed by $m i R-186-3 p$. The aforementioned data demonstrated that miR-186-3p could bind to MCM2. The antitumor function of si-MCM2 in cervical cancer has also been demonstrated (Fig. 3). The present study further explored the roles of miR-186-3p in cervical cancer and revealed that the 


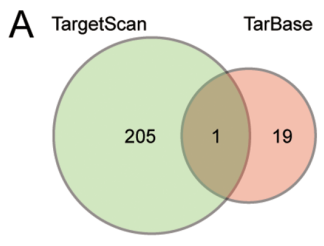
B Position 188-194 of MCM2 3'-UTR wt 5 '...CUUUGUGCUUCUCACCUUUGGGU...3' Hsa-miR-186-3p |||||| $\mid$
3' GGGUUUUUUAAGUGGAAACCCG 5'
Position 188-194 of MCM2 3'-UTR mut
5'....CUUUGUGCUUCUCACGAAACCCU...3'
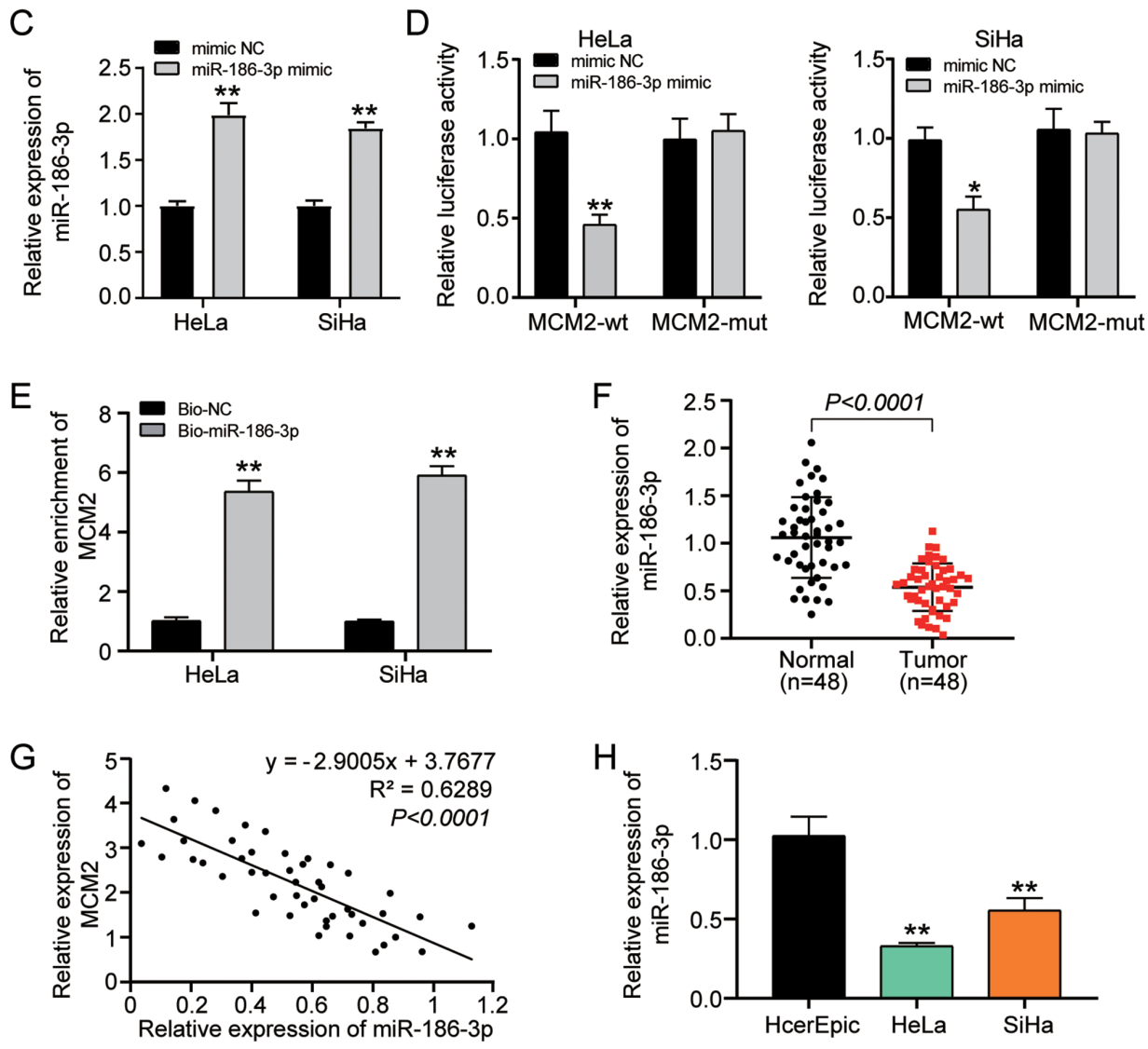

Figure 4. miR-186-3p directly targets MCM2. (A) TargetScan and TarBase predicted that miR-186-3p potentially regulated MCM2 expression. (B) Binding sites of MCM2 3' UTR for miR-186-3p. (C) Transfection efficiency of miR-186-3p mimic. ${ }^{* *} \mathrm{P}<0.001$ vs. mimic NC group (one-way ANOVA with Tukey's post hoc test). (D) Luciferase reporter assays were performed in both the mimic NC and miR-186-3p mimic groups by transfection with the plasmid of MCM2-wt or MCM2-mut in 3' UTR region. "P $<0.05,{ }^{* *} \mathrm{P}<0.001$ vs. co-transfection of MCM2-wt and mimic NC group (one-way ANOVA with Dunnett's post hoc test). (E) RNA pull-down assays were performed to demonstrate the interaction between MCM2 and miR-186-3p. ${ }^{* *} \mathrm{P}<0.001$ vs. Bio-NC group (one-way ANOVA with Tukey's post hoc test). (F) Expression levels of miR-186-3p in non-tumor tissues and tumor tissues. $\mathrm{P}<0.0001$ (paired Student's t-test). (G) Correlation between miR-186-3p expression and MCM2 expression in cervical cancer tissues. $(\mathrm{H})$ Relative expression levels of miR-186-3p in HcerEpic normal cervical epithelial cells and cervical cancer cell lines (HeLa and $\mathrm{SiHa}$ ). ${ }^{* *} \mathrm{P}<0.001$ vs. HcerEpic cells (one-way ANOVA with Dunnett's post hoc test). Bio-miR-186-3p, biotinylated miR-186-3p; Bio-NC, biotinylated negative control; MCM2, minichromosome maintenance complex component 2; mimic NC, miR-186-3p mimic negative control; miR-186-3p, microRNA-186-3p; mut, mutant; UTR, untranslated region; wt, wild-type.

expression levels of MCM2 were increased in the inhibitor group compared with the CON group; however, MCM2 knockdown did not affect the expression levels of miR-186-3p (Figs. 5A and S1). It was also observed that miR-186-3p inhibitor enhanced cell proliferation at 48 and $72 \mathrm{~h}$; however, the co-transfection of si-MCM2 and miR-186-3p inhibitor reversed the effect of si-MCM2 (Fig. 5B). In addition, the BrdU assay results demonstrated that cell proliferation was induced by silencing of miR-186-3p; however, the co-transfection of si-MCM2 and miR-186-3p inhibitor reversed the effect of si-MCM2 (Fig. 5C). Furthermore, miR-186-3p inhibitor enhanced the adhesive ability of the cells but MCM2 downregulation reversed the positive effect of miR-186-3p inhibitor (Fig. 5D). Additionally, the miR-186-3p inhibitor inhibited caspase-3/7 activity by $80 \%$ but the inhibitory effect of miR-186-3p inhibitor could be reversed by inhibiting MCM2 expression (Fig. 5E). The migration assay results demonstrated that miR-186-3p inhibitor increased cell migration by 2 -fold, and co-transfection of si-MCM2 and miR-186-3p inhibitor reversed the effect of si-MCM2 (Fig. 5F). When investigating the effect of miR-186-3p on the cell cycle, it was identified that the miR-186-3p inhibitor reversed the $\mathrm{G}_{0} / \mathrm{G}_{1}$ phase arrest caused by si-MCM2 (Fig. 5G and $\mathrm{H})$. Collectively, these results suggested that miR-186-3p suppressed cervical cancer tumours. By downregulating MCM2 expression, miR-186-3p impeded the proliferation and migration of cervical cancer cells and enhanced cervical cancer cell apoptosis. 


\section{A}
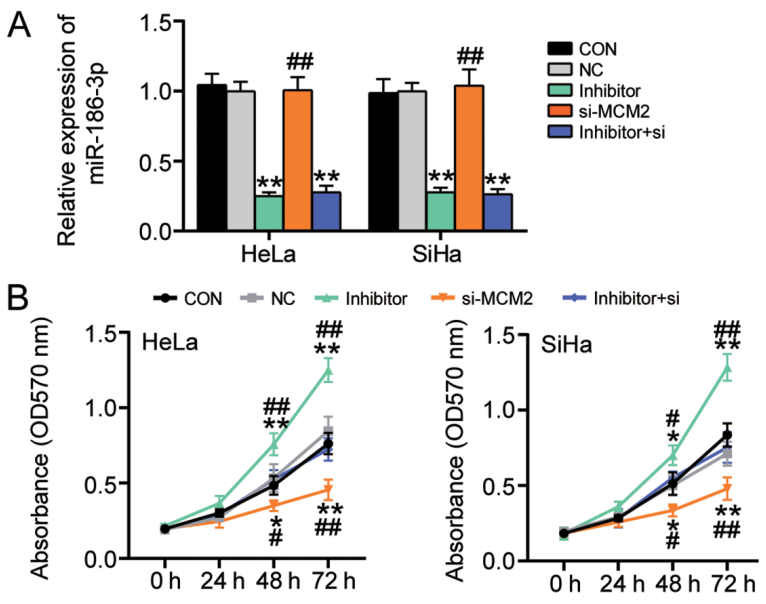

$\mathrm{D}$
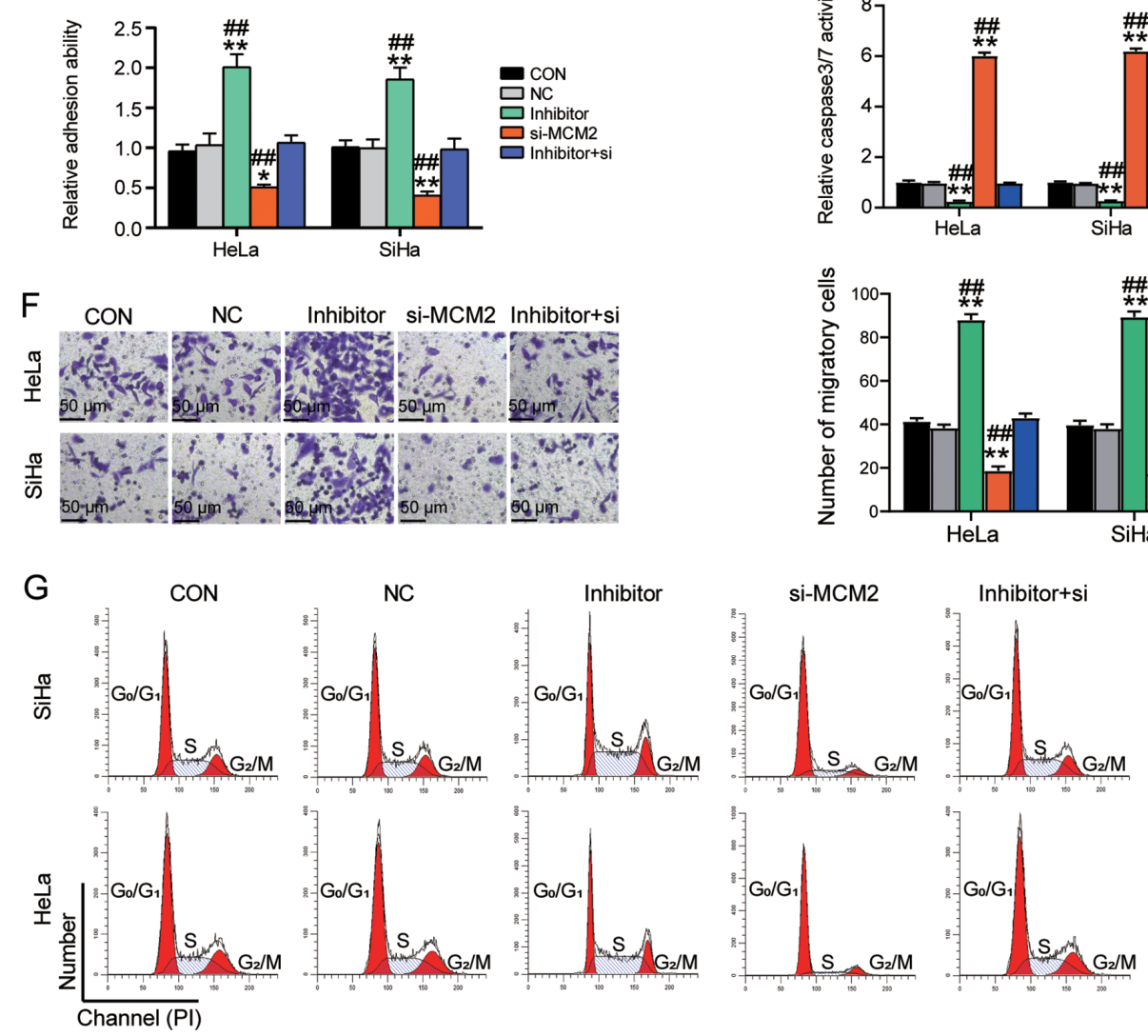
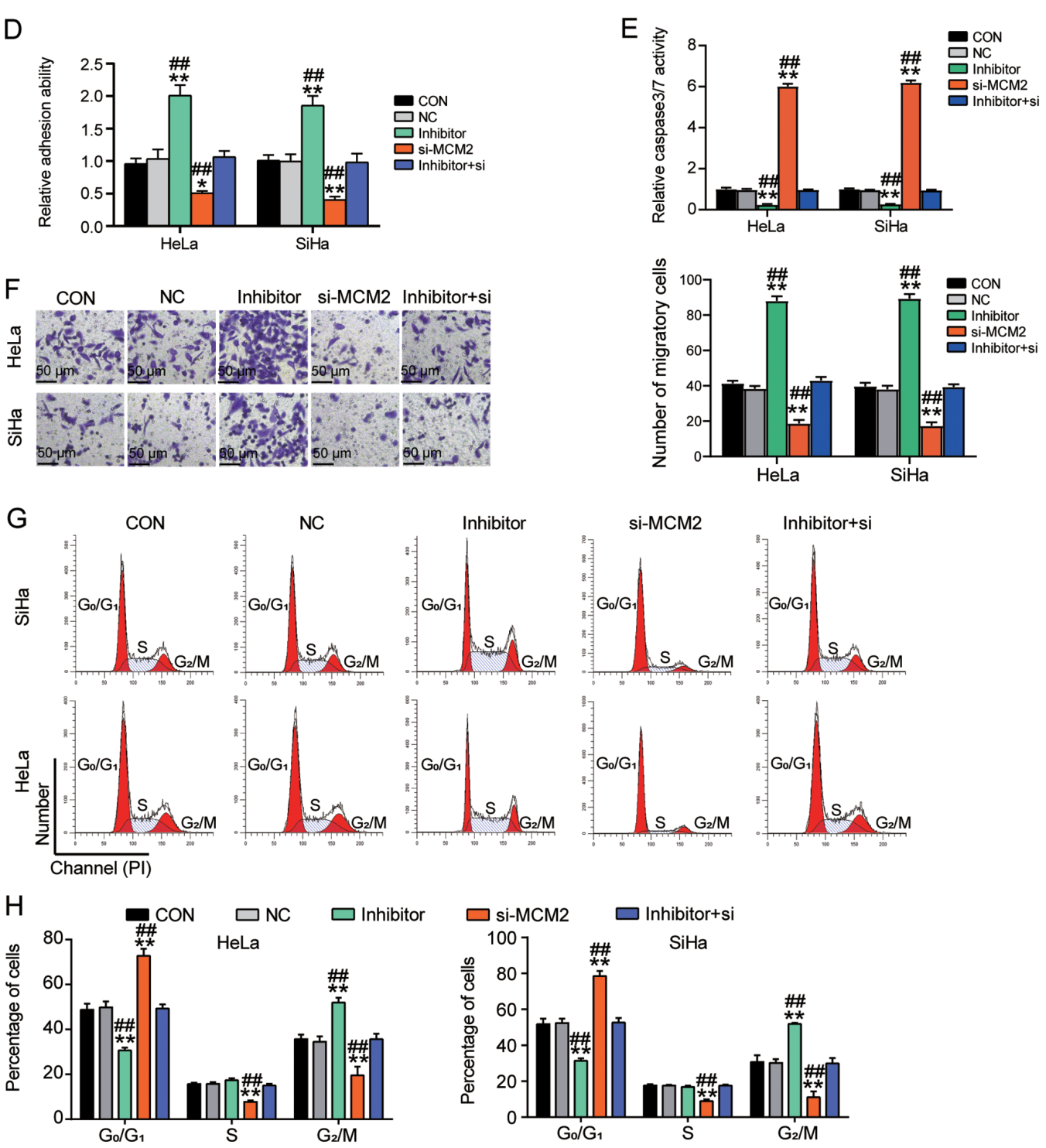

Figure 5. Effect of MCM2 on cervical cancer cells could be reversed by negative regulation from miR-186-3p. (A) Expression levels of miR-186-3p and MCM2 in the CON, NC, miR-186-3p inhibitor, si-MCM2 and inhibitor+si-MCM2 groups measured by reverse transcription-quantitative PCR. (B) MTT assays were performed to evaluate the proliferation of cells in the CON, NC, miR-186-3p inhibitor, si-MCM2 and inhibitor+si-MCM2 groups. (C) BrdU assays were performed to validate the effect of miR-186-3p on cell proliferation. (D) Cell adhesion assays were performed for the CON, NC, miR-186-3p inhibitor, si-MCM2 and inhibitor+si-MCM2 groups. (E) Caspase-3/7 activity in the CON, NC, miR-186-3p inhibitor, si-MCM2 and inhibitor+si-MCM2 groups to assess the effect on apoptosis mediated by miR-186-3p. (F) Cell migration assays were performed for cells in the CON, NC, miR-186-3p inhibitor, si-MCM2 and inhibitor+si-MCM2 groups. Scale bar, $50 \mu \mathrm{m}$. (G) Representative images of cell cycle in the CON, NC, miR-186-3p inhibitor, si-MCM2 and inhibitor+si-MCM2 groups. (H) Cell cycle distribution in the CON, NC, miR-186-3p inhibitor, si-MCM2 and inhibitor+si-MCM2 groups was calculated ${ }^{*} \mathrm{P}<0.05,{ }^{* *} \mathrm{P}<0.001$ vs. CON group (one-way ANOVA with Tukey's post hoc test). ${ }^{*} \mathrm{P}<0.05,{ }^{\# /} \mathrm{P}<0.001$ vs. inhibitor+si group (one-way ANOVA with Tukey's post hoc test). BrdU, 5-bromo-2-deoxyuridine; CON, blank control; MCM2, minichromosome maintenance complex component 2; miR-186-3p, microRNA-186-3p; NC, negative control; OD, optical density; si, small interfering RNA. 


\section{Discussion}

Cervical cancer is one of the most malignant cancer types and has a high mortality rate among women (1). Annually, $>500,000$ women are diagnosed with cervical cancer, and this tumour is responsible for $>300,000$ deaths worldwide (36). Although HPV infection has been demonstrated to be the main cause of cervical cancer, several unknown oncogenes promote cervical cancer progression (37). The present study revealed that MCM2 influenced cervical cancer cells and its expression was higher in tumour tissues than in non-tumour tissues. Knocking down MCM2 attenuated the proliferation and $G_{0} / G_{1}$ to $S$ phase transition of cervical cancer cells. Furthermore, miR-186-3p inhibitor increased the expression of MCM2 by binding to the 3' UTR region of the mRNA. The results revealed that by targeting MCM2, miR-186-3p could reverse the inhibitory effect on cell proliferation, $G_{0} / G_{1}$ to $\mathrm{S}$ phase transition and cell adhesion.

The cell cycle involves a series of events that occur within a cell, and these events include cell proliferation and division (38). Drugs target vital molecules that regulate the cell cycle. For instance, CDK4/CDK6 influences several malignant tumours, including breast cancer, oesophageal cancer and acute myeloid leukaemia (39-42). Although drugs targeting cell cycle molecules have not been approved for cervical cancer therapy, the genes regulating the cell cycle are under investigation $(43,44)$. For example, the inhibition of ASF1B induces cell cycle arrest in cervical cancer cells (43). Shen et al (45) demonstrated that claudin 1 induces cell cycle arrest in cervical squamous cell carcinoma. In the present study, it was revealed that MCM2 expression was upregulated in cervical cancer tissues and cell lines and that silencing MCM2 induced cell cycle arrest at the $\mathrm{G}_{0} / \mathrm{G}_{1}$ phase. These findings suggest that MCM 2 regulates the cell cycle and promotes the development of cervical cancer.

Furthermore, the MCM family is encoded by components involved in the initiation of genome replication (46). Upregulation of the MCM family is associated with the invasion of bladder cancer (47) and poor prognosis of breast cancer $(48)$. Previous studies $(25,28)$ have reported that HPV-infected cervical cancer cells exhibit high MCM2 expression, which is associated with a high risk of cervical cancer. Based on a clinical study on MCM2 in cervical cancer, the present study further explored the functions of MCM2 in cervical cancer cells and revealed that MCM2 acted as a tumour promoter in cervical cancer by inducing cell proliferation, cell adhesion and cell cycle progression.

In the last three decades, miRNAs have been revealed to regulate gene expression. In humans, $>1,000$ types of miRNAs influence the expression of more than one-third of the target genes and contribute to multiple alterations in cellular functions $(49,50)$. As a member of the miRNA family, miR-186-3p decreases the expression levels of CDK1 and causes $\mathrm{G}_{2} / \mathrm{M}$ cell cycle arrest in hepatocytes (51), indicating that this miRNA can regulate the cell cycle. These results are in agreement with the present findings. In breast cancer, the downregulation of miR-186-3p increases EREG expression, promotes aerobic glycolysis and accelerates cell proliferation (16), and this was verified in the present study. Indeed, low expression levels of miR-186 not only contribute to the anti-apoptosis ability and enhancement of metastasis in cervical cancer cells (18) but also act as a sponge of lncRNA to facilitate cervical cancer progression $(19,52)$. Consistent with these findings, the present study revealed that miR-186-3p was downregulated in cervical cancer and inhibited cell proliferation, cell cycle progression and cell adhesion. Furthermore, miR-186-3p regulated the progression of cervical cancer cells by targeting MCM2. Therefore, the present study demonstrated that miR-186-3p regulated MCM2 expression in cervical cancer, thereby facilitating cell proliferation and $\mathrm{G}_{0} / \mathrm{G}_{1}$ to $\mathrm{S}$ phase transition and reducing cell apoptosis by inhibiting MCM2 expression.

Although the present study demonstrated the oncogenic effects of MCM2 in terms of facilitating cell proliferation and influencing cell apoptosis, the present study had some limitations. No in vivo experiments were performed, and all results were based on a cellular function investigation and analysis of patient tissues. In addition, the present study did not investigate the downstream mechanism of MCM2 in accelerating cell proliferation. Therefore, future studies should explore downstream signalling pathways and key proteins involved in the process.

In summary, the present study suggested that by targeting MCM2, miR-186-3p inhibitor contributed to the proliferation, adhesion, migration and cell cycle progression of cervical cancer cells and inhibited apoptosis of cervical cancer cells. This research finding may enrich the understanding of the miRNA/oncogene regulatory axis in cervical cancer and provide novel insights for cervical cancer treatment.

\section{Acknowledgements}

Not applicable.

\section{Funding}

The present study was supported by Zhangjiakou City's 2020 Municipal Science and Technology Plan Self-Financing Project (grant no. 2021053D).

\section{Availability of data and materials}

The datasets used and/or analyzed during the present study are available from the corresponding author on reasonable request.

\section{Authors' contributions}

XRL, XS, XHH, XYL, XYZ, NY, HM and ZLZ performed the experiments and data analysis. XRL conceived and designed the study. XS wrote the paper. XRL, XHH, XYL, XYZ, NY, HM and ZLZ reviewed and edited the manuscript. HM and ZLZ confirm the authenticity of all the raw data. All authors read and approved the final manuscript.

\section{Ethics approval and consent to participate}

The present study was approved by the Ethics Committee of the First Affiliated Hospital of Hebei North University (Zhangjiakou, China). The processing of clinical tissue samples was in strict compliance with the ethical standards of the Declaration of Helsinki. All patients signed the written informed consent form. 


\section{Patient consent for publication}

Not applicable.

\section{Competing interests}

The authors declare that they have no competing interests.

\section{References}

1. Arbyn M, Weiderpass E, Bruni L, de Sanjosé S, Saraiya M, Ferlay $\mathrm{J}$ and Bray F: Estimates of incidence and mortality of cervical cancer in 2018: A worldwide analysis. Lancet Glob Health 8: e191-e203, 2020.

2. Brisson M and Drolet M: Global elimination of cervical cancer as a public health problem. Lancet Oncol 20: 319-321, 2019.

3. Simms KT, Steinberg J, Caruana M, Smith MA, Lew JB Soerjomataram I, Castle PE, Bray F and Canfell K: Impact of scaled up human papillomavirus vaccination and cervical screening and the potential for global elimination of cervical cancer in 181 countries, 2020-99: A modelling study. Lancet Oncol 20: 394-407, 2019.

4. Lin C, Slama J, Gonzalez P, Goodman MT, Xia N, Kreimer AR, Wu T, Hessol NA, Shvetsov Y, Ortiz AP, et al: Cervical determinants of anal HPV infection and high-grade anal lesions in women: A collaborative pooled analysis. Lancet Infect Dis 19: 880-891, 2019.

5. Yang J, Cai H, Xiao ZX, Wang H and Yang P: Effect of radiotherapy on the survival of cervical cancer patients: An analysis based on SEER database. Medicine (Baltimore) 98: e16421, 2019.

6. Inui M, Martello G and Piccolo S: MicroRNA control of signal transduction. Nat Rev Mol Cell Biol 11: 252-263, 2010.

7. Lu Y, Zhou Y, Qu W, Deng M and Zhang C: A Lasso regression model for the construction of microRNA-target regulatory networks. Bioinformatics 27: 2406-2413, 2011.

8. Cao C, Sun D, Zhang L and Song L: miR-186 affects the proliferation, invasion and migration of human gastric cancer by inhibition of Twist1. Oncotarget 7: 79956-79963, 2016.

9. Dong S, Wang R, Wang H, Ding Q, Zhou X, Wang J, Zhang K, Long Y, Lu S, Hong T, et al: HOXD-AS1 promotes the epithelial to mesenchymal transition of ovarian cancer cells by regulating miR-186-5p and PIK3R3. J Exp Clin Cancer Res 38: 110, 2019.

10. Liu Z, Zhang G, Yu W, Gao N and Peng J: miR-186 inhibits cell proliferation in multiple myeloma by repressing Jagged1. Biochem Biophys Res Commun 469: 692-697, 2016.

11. Su BB, Zhou SW, Gan CB and Zhang XN: miR-186 inhibits cell proliferation and invasion in human cutaneous malignant melanoma. J Cancer Res Ther 14 (Suppl): S60-S64, 2018.

12. Qiu H, Yuan S and Lu X: miR-186 suppressed CYLD expression and promoted cell proliferation in human melanoma. Oncol Lett 12: 2301-2306, 2016.

13. Liu L, Wang Y, Bai R, Yang K and Tian Z: miR-186 inhibited aerobic glycolysis in gastric cancer via HIF-1 $\alpha$ regulation. Oncogenesis 5: e224, 2016

14. Yao K, He L, Gan Y,Zeng Q, Dai Y and Tan J: miR-186 suppresses the growth and metastasis of bladder cancer by targeting NSBP1. Diagn Pathol 10: 146, 2015.

15. Wang R, Bao H, Zhang S, Li R, Chen L and Zhu Y: miR-186-5p Promotes Apoptosis by Targeting IGF-1 in SH-SY5Y OGD/R Model. Int J Biol Sci 14: 1791-1799, 2018.

16. He M, Jin Q, Chen C, Liu Y, Ye X, Jiang Y, Ji F, Qian H, Gan D, Yue S, et al: The miR-186-3p/EREG axis orchestrates tamoxifen resistance and aerobic glycolysis in breast cancer cells. Oncogene 38: 5551-5565, 2019.

17. Honegger A, Schilling D, Bastian S, Sponagel J, Kuryshev V, Sültmann H, Scheffner M, Hoppe-Seyler K and Hoppe-Seyler F: Dependence of intracellular and exosomal microRNAs on viral E6/E7 oncogene expression in HPV-positive tumor cells. PLoS Pathog 11: e1004712, 2015.

18. Liu C, Wang J, Hu Y, Xie H, Liu M and Tang H: Upregulation of kazrin F by miR-186 suppresses apoptosis but promotes epithelial-mesenchymal transition to contribute to malignancy in human cervical cancer cells. Chin J Cancer Res 29: 45-56, 2017.

19. Zhang JJ, Wang DD, Du CX and Wang Y: Long Noncoding RNA ANRIL Promotes Cervical Cancer Development by Acting as a Sponge of miR-186. Oncol Res 26: 345-352, 2018.
20. Kucherlapati M: Examining transcriptional changes to DNA replication and repair factors over uveal melanoma subtypes. BMC Cancer 18: 818, 2018.

21. Lei M, Kawasaki Y, Young MR, Kihara M, Sugino A and Tye BK: Mcm2 is a target of regulation by Cdc7-Dbf4 during the initiation of DNA synthesis. Genes Dev 11: 3365-3374, 1997.

22. Issac MSM, Yousef E, Tahir MR and Gaboury LA: MCM2, MCM4, and MCM6 in Breast Cancer: Clinical Utility in Diagnosis and Prognosis. Neoplasia 21: 1015-1035, 2019.

23. Gad SA, Ali HEA, Gaballa R, Abdelsalam RM, Zerfaoui M, Ali HI, Salama SH, Kenawy SA, Kandil E and Abd Elmageed ZY: Targeting CDC7 sensitizes resistance melanoma cells to BRAFV600E-specific inhibitor by blocking the CDC7/MCM2-7 pathway. Sci Rep 9: 14197, 2019.

24. Aihemaiti G, Kurata M, Nogawa D, Yamamoto A, Mineo T, Onishi I, Kinowaki Y, Jin XH, Tatsuzawa A, Miyasaka N, et al: Subcellular localization of MCM2 correlates with the prognosis of ovarian clear cell carcinoma. Oncotarget 9: 28213-28225, 2018.

25. Al-Hazmi N, Alhazzazi T, Williams G, Stoeber K and Al-Dabbagh R: DNA replication licensing factor MCM2, geminin, and Ki67 define proliferative state and are linked with survival in oral squamous cell carcinoma. Eur J Oral Sci 126: 186-196, 2018.

26. Kaur G, Balasubramaniam SD, Lee YJ, Balakrishnan V and Oon CE: Minichromosome Maintenance Complex (MCM) Genes Profiling and MCM2 Protein Expression in Cervical Cancer Development. Asian Pac J Cancer Prev 20: 3043-3049, 2019.

27. Tang $\mathrm{X}, \mathrm{Xu} \mathrm{Y,} \mathrm{Lu} \mathrm{L,} \mathrm{Jiao} \mathrm{Y,} \mathrm{Liu} \mathrm{J,} \mathrm{Wang} \mathrm{L} \mathrm{and} \mathrm{Zhao} \mathrm{H:}$ Identification of key candidate genes and small molecule drugs in cervical cancer by bioinformatics strategy. Cancer Manag Res 10: 3533-3549, 2018.

28. Amaro Filho SM, Nuovo GJ, Cunha CB, Ramos Pereira LO, Oliveira-Silva M, Russomano F, Pires A and Nicol AF: Correlation of MCM2 detection with stage and virology of cervical cancer. Int J Biol Markers 29: e363-e371, 2014.

29. Xu Z, Zhou Y, Shi F, Cao Y, Dinh TLA, Wan J and Zhao M: Investigation of differentially-expressed microRNAs and genes in cervical cancer using an integrated bioinformatics analysis. Oncol Lett 13: 2784-2790, 2017.

30. Zhai Y, Kuick R, Nan B, Ota I, Weiss SJ, Trimble CL, Fearon ER and Cho KR: Gene expression analysis of preinvasive and invasive cervical squamous cell carcinomas identifies HOXC10 as a key mediator of invasion. Cancer Res 67: 10163-10172, 2007.

31. den Boon JA, Pyeon D, Wang SS, Horswill M, Schiffman M, Sherman M, Zuna RE, Wang Z, Hewitt SM, Pearson R, et al: Molecular transitions from papillomavirus infection to cervical precancer and cancer: Role of stromal estrogen receptor signaling. Proc Natl Acad Sci USA 112: E3255-E3264, 2015.

32. Matsuo K, Machida H, Mandelbaum RS, Konishi I and Mikami M: Validation of the 2018 FIGO cervical cancer staging system. Gynecol Oncol 152: 87-93, 2019.

33. Powazniak Y, Kempfer AC, Pereyra JC, Palomino JP and Lazzari MA: VWF and ADAMTS13 behavior in estradiol-treated HUVEC. Eur J Haematol 86: 140-147, 2011.

34. Livak KJ and Schmittgen TD: Analysis of relative gene expression data using real-time quantitative PCR and the 2(-Delta Delta C(T)) Method. Methods 25: 402-408, 2001.

35. Zheng J: Diagnostic value of MCM2 immunocytochemical staining in cervical lesions and its relationship with HPV infection. Int J Clin Exp Pathol 8: 875-880, 2015.

36. Smith RA, Manassaram-Baptiste D, Brooks D, Doroshenk M, Fedewa S, Saslow D, Brawley OW and Wender R: Cancer screening in the United States, 2015: A review of current American cancer society guidelines and current issues in cancer screening. CA Cancer J Clin 65: 30-54, 2015.

37. Brisson M, Kim JJ, Canfell K, Drolet M, Gingras G, Burger EA, Martin D, Simms KT, Bénard É, Boily MC, et al: Impact of HPV vaccination and cervical screening on cervical cancer elimination: A comparative modelling analysis in 78 low-income and lower-middle-income countries. Lancet 395: 575-590, 2020.

38. Petroni G, Formenti SC, Chen-Kiang S and Galluzzi L: Immunomodulation by anticancer cell cycle inhibitors. Nat Rev Immunol 20: 669-679, 2020.

39. Romero-Pozuelo J, Figlia G, Kaya O, Martin-Villalba A and Teleman AA: Cdk4 and Cdk6 Couple the Cell-Cycle Machinery to Cell Growth via mTORC1. Cell Rep 31: 107504, 2020. 
40. Qie S, Yoshida A, Parnham S, Oleinik N, Beeson GC, Beeson CC, Ogretmen B, Bass AJ, Wong KK, Rustgi AK, et al: Targeting glutamine-addiction and overcoming CDK4/6 inhibitor resistance in human esophageal squamous cell carcinoma. Nat Commun 10: 1296, 2019.

41. Whittle JR, Vaillant F, Surgenor E, Policheni AN, Giner G, Capaldo BD, Chen HR, Liu HK, Dekkers JF, Sachs N, et al: Dual Targeting of CDK4/6 and BCL2 Pathways Augments Tumor Response in Estrogen Receptor-Positive Breast Cancer. Clin Cancer Res 26: 4120-4134, 2020.

42. Schmoellerl J, Barbosa IAM, Eder T, Brandstoetter T, Schmidt L, Maurer B, Troester S, Pham HTT, Sagarajit M, Ebner J, et al: CDK6 is an essential direct target of NUP98 fusion proteins in acute myeloid leukemia. Blood 136: 387-400, 2020.

43. Liu X, Song J, Zhang Y, Wang H, Sun H, Feng X, Hou M, Chen G, Tang Q and Ji M: ASF1B promotes cervical cancer progression through stabilization of CDK9. Cell Death Dis 11: 705, 2020.

44. Lee S, Ho JY, Liu JJ, Lee H, Park JY, Baik M, Ko M, Lee SU, Choi YJ and Hur SY: CKD-602, a topoisomerase I inhibitor, induces apoptosis and cell-cycle arrest and inhibits invasion in cervical cancer. Mol Med 25: 23, 2019.

45. Shen Z, Song W, Qian L, Zhu J, Li Y, Li M, Zhang T, Zhao W, Zhou Y and Yang X: Effect of claudin 1 on cell proliferation, migration and apoptosis in human cervical squamous cell carcinoma. Oncol Rep 45: 606-618, 2021.

46. Forsburg SL: Eukaryotic MCM proteins: Beyond replication initiation. Microbiol Mol Biol Rev 68: 109-131, 2004.
47. Roupret M, Gontero P, McCracken SRC, Dudderidge T, Stockley J, Kennedy A, Rodriguez O, Sieverink C, Vanié F, Allasia M, et al: Diagnostic Accuracy of MCM5 for the Detection of Recurrence in Nonmuscle Invasive Bladder Cancer Followup: A Blinded, Prospective Cohort, Multicenter European Study. J Urol 204: 685-690, 2020.

48. Zhao Y, Wang Y, Zhu F, Zhang J, Ma X and Zhang D: Gene expression profiling revealed MCM3 to be a better marker than Ki67 in prognosis of invasive ductal breast carcinoma patients. Clin Exp Med 20: 249-259, 2020.

49. Rachagani S, Macha MA, Heimann N, Seshacharyulu P, Haridas D, Chugh S and Batra SK: Clinical implications of miRNAs in the pathogenesis, diagnosis and therapy of pancreatic cancer. Adv Drug Deliv Rev 81: 16-33, 2015.

50. Garofalo $\mathrm{M}$ and Croce CM: Role of microRNAs in maintaining cancer stem cells. Adv Drug Deliv Rev 81: 53-61, 2015.

51. Yang R, Wei M, Yang F, Sheng Y and Ji L: Diosbulbin B induced G2/M cell cycle arrest in hepatocytes by miRNA-186-3p and miRNA-378a-5p-mediated the decreased expression of CDK1. Toxicol Appl Pharmacol 357: 1-9, 2018.

52. Liu Y, Guo R, Qiao Y, Han L and Liu M: LncRNA NNT-AS1 contributes to the cisplatin resistance of cervical cancer through NNT-AS1/miR-186/HMGB1 axis. Cancer Cell Int 20: 190, 2020.

This work is licensed under a Creative Commons

Attribution-NonCommercial-NoDerivatives 4.0 International (CC BY-NC-ND 4.0) License. 